\title{
Assessing the risk factors of preterm births in Kurdistan, Iran: a case-control study
}

\section{Siros Hemmatpour}

Kurdistan University of Medical Sciences

\section{Majid Mansori}

Kurdistan University of Medical Sciences

\section{Ghobad Moradi}

Kurdistan University of Medical Sciences

\section{Shobo Sheikhahmadi}

Kurdistan University of Medical Sciences

Batoul Bagheri ( $\nabla$ roz.baghery123456@gmail.com )

Kurdistan University of Medical Sciences https://orcid.org/0000-0002-6104-0642

\section{Research article}

Keywords: Infants, Preterm, term, Case control, Iran

Posted Date: February 11th, 2020

DOI: https://doi.org/10.21203/rs.2.23137/v1

License: (c) (i) This work is licensed under a Creative Commons Attribution 4.0 International License. Read Full License 


\section{Abstract}

Background: Preterm birth is one of the most common causes of mortality in infants. Despite advances in health care and better access to health services in many countries, preterm birth has increased over the past two decades.

Methods: This case control study was conducted on two groups with 100 participants including 100 preterm infants (case) and 100 term infants (control) with gender match in Kurdistan Province-Iran in 2018. The required information was collected from medical files and interviewing the mothers as to demographical information, midwifery specifications, background diseases, disease over pregnancy term, and infants' information. Conditional logistic regression test was used to estimate the final model and compute the risk ratio.

Results: Multivariate regression analysis showed that the risk of preterm birth in individual with $A B$ blood type was higher ( $\mathrm{OR}=5.04 ; 95 \% ; \mathrm{Cl} 1.40-18.08)$. In addition, the risk of preterm birth was higher in the mothers with a history of stillbirth $(\mathrm{OR}=13.63 ; 95 \% \mathrm{Cl} 1.39-133.5)$. Preterm birth was significantly related to the history of birth diseases, history of pregnancy diseases, and using medicine for specific diseases during pregnancy.

Conclusions: Blood type of mother, history of still birth, history of birth disease, history of pregnancy diseases, using medicines for specific diseases, and history of preterm birth were the risk factors of preterm birth. These factors need to be taken into account before and during pregnancy. Paying more attention to these factors attenuates the rate of preterm birth and premature infants and in turn the mortality rate of infants and mothers.

\section{Background}

Preterm child delivery is defined as birth before the 37th week or 259th day of pregnancy and it has a key factor in mortality and morbidity in infants, children, and even adults [1-3]. Based on pregnancy age and according to the World Health Organization (WHO), preterm birth is categorized as highly preterm birth (before 28th week), very preterm birth (28th -32nd week), and moderate and mild preterm birth (32nd 37 th week) [4]. Currently, preterm birth is the most common cause of death in infants. Mortality rate of infants is a measure of the quality of health system [5]. About $75 \%$ of prenatal deaths happen in preterm infants and more than $30 \%$ of these cases are in preterm birth before the 32nd week of pregnancy [4]. As shown by different studies, the prevalence of preterm birth in Asia ranges from $7.2-13.6 \%$ and $5.6-34.9 \%$ $[6,7]$. According to WHO (2018) the highest mortality rates of preterm infant (per 100 live births) were in Malawi (18.1), Comoros (16.7\%), Kongo (16.7\%), Zimbabwe (16.6\%), Equatorial Guinea (16.5\%), Mozambique (16.4\%), Gabon (16.3\%), Pakistan (15.8\%), Indonesia (15.5\%), and Mauritania (15.4\%) [8].

Preterm birth is a multi-cause event and it is related to genetic, environment, and immunology factors [1, 9]. The main causes of preterm birth in the developing countries are infectious diseases and lack of access to health cares. In the case of developed countries, mothers' age and an increase in multiple 
pregnancy due to pregnancy medicines are the main causes of preterm birth $[10,11]$. Case-control studies in different provinces of Iran have shown that ethnicity, history of abortion and preterm birth, irregular menstrual cycle, cousin marriage, and pregnancies with short gap were the main causes of preterm birth [1].

Although, there are several risk factors in preterm birth, the whole etiology is not uncovered yet [12]. In addition, despite the advances in health care and higher access to health services in many countries, the past two decades have witnessed an increase in preterm birth. Therefore, it is essential to have a deeper insight into the risk factors of preterm birth. The present study is an attempt to examine the risk factors of premature birth in Kurdistan Province-Iran.

\section{Methods}

\section{Data source}

A case-control study was carried out on two groups of preterm infants $(n=100$; case) and term infants ( $n$ = 100; control) in Besaat Hospital, Sannadaj-Kurdistan (2018). The participants were selected through census sampling. Inclusion criterion in the case group was women with pregnancy age less than 37 weeks and in the case of control group, women with pregnancy age of more than 37 weeks. The two groups were homogenized in terms of infants' gender. The information was gleaned from medical files and interviewing the mothers in five areas of demographics, midwifery specifications, background diseases, pregnancy diseases, and infant information. Individuals with a history of intrauterine fetal death (IUFD), abortion, psychological, systemic, and metabolic diseases were excluded. All participants were informed about the purpose and process of the study, and written informed consent for participation in the study was obtained from the participants. The approval for this study was obtained from the Ethics Committee of Kurdistan University of Medical Science (IR.MUK.REC.1398.051).

\section{Statistical analysis}

Frequency and percentage of each one of the variables were calculated for the both groups and the relationship between qualitative and quantitative independent or depended variables was examined using chi-square and t-tests. To obtain the final model, the variables with $P<0.20$ were examined using univariate logistic analysis and adjusted odds ratio (OR) was obtained using conditional logistic regression. $\mathrm{P}<0.05$ was considered statistically significant. All statistical analyses were performed using Stata14.0 software (StataCorp, College Station, TX).

\section{Results}

As the results showed, $71 \%$ and $78 \%$ of the case and control groups were city dwellers respectively and $12 \%$ and $21 \%$ of the case and control groups had a college degree respectively. Cousin marriage in the case and control groups were $13 \%$ and $19 \%$ respectively. Frequency of the history of smoking or exposure of cigarette was higher in the case group than the control group. Spiritual and mental tensions in the case 
group was higher than the control group. Frequency of blood type in the case and control groups was different; so that the highest and lowest frequencies of blood type in the two group were $O$ and $A B$ respectively $(P<0.001$. Frequency of stillbirth in the case and control groups were $8 \%$ and $1 \%$ respectively $(P=0.017)$.

Background diseases (diabetes, hypertension, epilepsy, anemia, urinary infection, hyper/hypothyroid, mouth and teeth problems, etc.), pregnancy disease (history of pregnancy bleeding, uterus anomaly, pregnancy diabetes, vaginal bleeding during the third three months, cardiac disease during pregnancy, renal disease during pregnancy, polyhydramnios, history of alkilo hydramnios, and history of trauma) in the case group was significantly higher than the control group ( $P=0.048)$. More than $95 \%$ of the case and control groups used pharmaceutical supplements (Table 1). The results about the other quantitative variables like number of pregnancies, number of term births, number of abortions, BMI, birth order, and mother's hemoglobin level are listed in Table 1.

Table 1. Demographic information and other characteristics in cases and control groups 
Table 1

\begin{tabular}{|c|c|c|c|c|}
\hline \multicolumn{2}{|l|}{ Characteristic Category } & \multirow{2}{*}{$\begin{array}{l}\text { Control } \\
\mathrm{N}=100\end{array}$} & \multirow{2}{*}{$\begin{array}{l}\text { Case } \\
N=100 \\
50\end{array}$} & \multirow{2}{*}{$\begin{array}{l}P \\
\text { value } \\
1\end{array}$} \\
\hline Sex & Girl & & & \\
\hline & Boy & 50 & 50 & \\
\hline \multirow[t]{2}{*}{ Place of Residence } & City & 71 & 78 & \multirow[t]{2}{*}{0.256} \\
\hline & Rural & 29 & 22 & \\
\hline \multirow[t]{3}{*}{ Level of Education (Mother) } & Academic & 12 & 21 & \multirow[t]{3}{*}{0.139} \\
\hline & Under diploma & 80 & 75 & \\
\hline & Illiterate & 8 & 4 & \\
\hline \multirow[t]{3}{*}{ Level of Education (Father) } & Academic & 32 & 23 & \multirow[t]{3}{*}{0.310} \\
\hline & Under diploma & 64 & 74 & \\
\hline & Illiterate & 4 & 3 & \\
\hline \multirow[t]{2}{*}{ Residence } & $\begin{array}{l}\text { Center of } \\
\text { province }\end{array}$ & 49 & 68 & \multirow[t]{2}{*}{0.330} \\
\hline & Other cities & 51 & 32 & \\
\hline \multirow[t]{2}{*}{ Have family relative } & No & 87 & 81 & \multirow[t]{2}{*}{0.247} \\
\hline & Yes & 13 & 19 & \\
\hline \multirow[t]{2}{*}{ History of divorce } & No & 84 & 86 & \multirow[t]{2}{*}{0.692} \\
\hline & Yes & 16 & 14 & \\
\hline \multirow[t]{2}{*}{ Smoking } & No & 92 & 98 & \multirow[t]{2}{*}{0.052} \\
\hline & Yes & 8 & 2 & \\
\hline \multirow[t]{2}{*}{ Passive smoker } & No & 53 & 62 & \multirow[t]{2}{*}{0.218} \\
\hline & Yes & 47 & 38 & \\
\hline \multirow[t]{2}{*}{ Spiritual and mental tensions } & No & 70 & 75 & \multirow[t]{2}{*}{0.428} \\
\hline & Yes & 30 & 25 & \\
\hline \multirow[t]{3}{*}{ Blood type } & A & 23 & 31 & \multirow{3}{*}{$\begin{array}{l}<.001 \\
0.00\end{array}$} \\
\hline & B & 24 & 18 & \\
\hline & $A B$ & 20 & 4 & \\
\hline
\end{tabular}




\begin{tabular}{|c|c|c|c|c|}
\hline \multirow[t]{2}{*}{ Characteristic Category } & & Control & Case & \\
\hline & 0 & 33 & 47 & \\
\hline \multirow[t]{2}{*}{$\mathrm{RH}$} & Positive & 94 & 89 & \multirow[t]{2}{*}{0.311} \\
\hline & Negative & 6 & 11 & \\
\hline \multirow[t]{2}{*}{ Stillbirth history } & No & 99 & 92 & \multirow[t]{2}{*}{0.017} \\
\hline & Yes & 1 & 8 & \\
\hline \multirow[t]{2}{*}{ Recently pregnancy with IVF } & No & 78 & 81 & \multirow[t]{2}{*}{0.599} \\
\hline & Yes & 22 & 19 & \\
\hline \multirow[t]{2}{*}{ Background diseases } & No & 39 & 56 & \multirow[t]{2}{*}{0.016} \\
\hline & Yes & 61 & 44 & \\
\hline \multirow[t]{2}{*}{ History of pregnancy disease } & No & 58 & 44 & \multirow[t]{2}{*}{0.048} \\
\hline & Yes & 42 & 56 & \\
\hline \multirow{2}{*}{$\begin{array}{l}\text { History of used pharmaceutical } \\
\text { supplements }\end{array}$} & No & 1 & 3 & \multirow[t]{2}{*}{0.621} \\
\hline & Yes & 99 & 97 & \\
\hline \multirow{3}{*}{$\begin{array}{l}\text { History time of used pharmaceutical } \\
\text { supplements }\end{array}$} & $<1$ month & 0 & 4 & \multirow[t]{3}{*}{0.055} \\
\hline & $1-3$ month & 1 & 4 & \\
\hline & $>3$ month & 99 & 92 & \\
\hline \multirow[t]{2}{*}{ Twins } & No & 99 & 71 & \multirow{2}{*}{$\dot{0.001}$} \\
\hline & Yes & 1 & 29 & \\
\hline \multirow[t]{2}{*}{ Taking medicine (specific illness) } & No & 24 & 46 & \multirow[t]{2}{*}{0.001} \\
\hline & Yes & 76 & 54 & \\
\hline \multirow[t]{2}{*}{ Pregnancy Care } & No & 3 & 0 & \multirow[t]{2}{*}{0.246} \\
\hline & Yes & 97 & 100 & \\
\hline \multirow[t]{3}{*}{ Stillbirth } & No & 92 & 79 & \multirow[t]{2}{*}{0.009} \\
\hline & Yes & 8 & 21 & \\
\hline & & Mean (SD) & Mean (SD) & \\
\hline Age (Mother's) & & $30.2(6.03)$ & $31.2(5.68)$ & 0.220 \\
\hline
\end{tabular}




\begin{tabular}{|llll|}
\hline Characteristic Category & $\begin{array}{l}\text { Control } \\
\mathbf{N}=100\end{array}$ & $\begin{array}{l}\text { Case } \\
\mathbf{N}=100\end{array}$ & $\begin{array}{l}\mathbf{P} \\
\text { value }\end{array}$ \\
\hline Number of pregnancy & $2.07(1.05)$ & $2.26(1.24)$ & 0.246 \\
\hline Number of giving birth & $1.66(0.81)$ & $1.94(1.17)$ & 0.050 \\
\hline Number of abortion & $1.3(0.54)$ & $1.21(0.49)$ & 0.531 \\
\hline BMI & 67.60 & 67.76 & 0.920 \\
\hline Hemoglobin level & $(10.83)$ & $(11.52)$ & \\
\hline Birth order & $11.7(1.1)$ & $11.5(0.8)$ & 0.115 \\
\hline SD: Standard Deviation & $1.66(0.84)$ & $1.90(1.11)$ & 0.098 \\
\hline
\end{tabular}

The results of univariate analysis showed that the risk of preterm birth in mothers with $A B$ blood type (OR $=5.36 ; P=0.003)$ was higher. In addition, the risk of preterm birth was higher in the mothers with a history of stillbirth $(O R=8.60 ; P=0.016)$, mothers with a history of background disease $(O R=1.99 ; P=0.017)$, mothers with pregnancy disease $(O R=175 ; P=0.048)$, mothers with a history of multiple pregnancy (OR $=38.5 ; \mathrm{P}<0.001)$, mothers who used medicine for a specific disease $(\mathrm{OR}=1.69 ; \mathrm{P}=0.001)$; and mothers with a history of premature birth $(\mathrm{OR}=3.08 ; \mathrm{P}=0.012)$ (Table 2$)$. The multivariate regression analysis showed that the risk of preterm birth in women with $A B$ blood type was higher than other blood types (OR $=5.04 ; 95 \% \mathrm{Cl} 1.40-18.08)$. In addition, the risk of preterm birth in the mothers with a history of stillbirth was higher $(\mathrm{OR}=13.63 ; 95 \% \mathrm{Cl} 1.39-133.5)$. The risk of preterm birth was higher in mothers with a history of pregnancy diseases $(\mathrm{OR}=2.27 ; 95 \% \mathrm{Cl} 1.07-4.21)$ and the mothers who used medicine for specific diseases during pregnancy $(\mathrm{OR}=3 ; 95 \% \mathrm{Cl} 1.24-6.25)$. The risk of preterm birth in women with a history of premature birth was higher in the case group $(\mathrm{OR}=4.06 ; 95 \% \mathrm{Cl} 1.44-11.49)$ (Table 2).

Table 2. Univariate and Multivariate logistic regression of risk factors for preterm delivery 
Table 2

\begin{tabular}{|c|c|c|c|c|c|c|c|}
\hline \multicolumn{2}{|l|}{ Characteristic Category } & \multirow{2}{*}{$\begin{array}{l}\text { Control } \\
\mathrm{N}= \\
100\end{array}$} & \multirow{2}{*}{$\begin{array}{l}\text { Case } \\
N= \\
100\end{array}$} & \multirow{2}{*}{$\begin{array}{l}\text { OR Crude } \\
(95 \% \mathrm{Cl})\end{array}$} & \multirow{2}{*}{$\begin{array}{l}P \\
\text { value }\end{array}$} & \multirow{2}{*}{$\begin{array}{l}\text { OR Adjusted } \\
(95 \% \mathrm{Cl})\end{array}$} & \multirow{2}{*}{$\begin{array}{l}P \\
\text { value }\end{array}$} \\
\hline & & & & & & & \\
\hline \multirow[t]{4}{*}{ Blood type } & $A$ & 23 & 31 & 1 & - & 1 & - \\
\hline & $\mathrm{B}$ & 24 & 18 & $\begin{array}{l}1.79(0.79- \\
4.06)\end{array}$ & 0.159 & $\begin{array}{l}1.66(0.52- \\
3.81)\end{array}$ & 0.517 \\
\hline & $A B$ & 20 & 4 & $\begin{array}{l}5.39(1.76- \\
16.50)\end{array}$ & 0.003 & $\begin{array}{l}5.04(1.40- \\
18.08)\end{array}$ & 0.013 \\
\hline & 0 & 33 & 47 & $\begin{array}{l}0.96(0.46- \\
1.94)\end{array}$ & 0.925 & $\begin{array}{l}0.74(0.31- \\
1.71)\end{array}$ & 0.502 \\
\hline \multirow[t]{2}{*}{ History of stillbirth } & No & 99 & 92 & 1 & \multirow[t]{2}{*}{0.016} & 1 & \multirow[t]{2}{*}{0.025} \\
\hline & Yes & 1 & 8 & $\begin{array}{l}8.60(1.05- \\
70.1)\end{array}$ & & $\begin{array}{l}13.63(1.39- \\
133.5)\end{array}$ & \\
\hline \multirow[t]{2}{*}{ Background diseases } & No & 39 & 56 & 1 & \multirow[t]{2}{*}{0.017} & 1 & \multirow[t]{2}{*}{0.519} \\
\hline & Yes & 61 & 44 & $\begin{array}{l}1.99(1.13- \\
3.49)\end{array}$ & & $\begin{array}{l}1.27(0.61- \\
2.64)\end{array}$ & \\
\hline \multirow{2}{*}{$\begin{array}{l}\text { History of pregnancy } \\
\text { disease }\end{array}$} & No & 58 & 44 & - & \multirow[t]{2}{*}{0.048} & 1 & \multirow[t]{2}{*}{0.028} \\
\hline & Yes & 42 & 56 & $\begin{array}{l}1.75(1- \\
3.07)\end{array}$ & & $\begin{array}{l}2.27(1.07- \\
4.21)\end{array}$ & \\
\hline \multirow[t]{2}{*}{ Twins } & No & 99 & 71 & 1 & \multirow{2}{*}{$<.001$} & 1 & \multirow{2}{*}{$\begin{array}{l}< \\
0.001\end{array}$} \\
\hline & Yes & 1 & 29 & $\begin{array}{l}38.5(5.11- \\
289)\end{array}$ & & $\begin{array}{l}62.9(7.96- \\
499.2)\end{array}$ & \\
\hline \multirow{2}{*}{$\begin{array}{l}\text { Taking medicine } \\
\text { (specific illness) }\end{array}$} & No & 24 & 46 & 1 & \multirow[t]{2}{*}{0.001} & 1 & \multirow[t]{2}{*}{0.003} \\
\hline & Yes & 76 & 54 & $\begin{array}{l}1.69(1.47- \\
4.93)\end{array}$ & & $\begin{array}{l}3(1.24- \\
6.25)\end{array}$ & \\
\hline \multirow{2}{*}{$\begin{array}{l}\text { Birth history of } \\
\text { premature infant }\end{array}$} & No & 92 & 79 & 1 & \multirow[t]{2}{*}{0.012} & 1 & \multirow[t]{2}{*}{0.011} \\
\hline & Yes & 8 & 21 & $\begin{array}{l}3.05(1.28- \\
7.28)\end{array}$ & & $\begin{array}{l}4.06(1.44- \\
11.49)\end{array}$ & \\
\hline
\end{tabular}

\section{Discussion}

Preterm birth was significantly related to the history of stillbirth, blood type, history of premature birth, mother's diseases, and using specific medicines during pregnancy. Although, advances in pediatric medicine and novel methods of infant care have increased the survival chance of preterm infants, the rate of preterm birth has remained almost unchanged and a serious challenge for health system. 
The risk of preterm birth in women with a history of stillbirth was higher in the case group comparing with the control group. Soltani et al. showed that the risk of preterm birth in women with a history of stillbirth was four times higher than women without it [1]. Malacova et al. reported that the risk of preterm birth in women with a history of stillbirth was three to four times higher. They also showed that the risk of preterm birth in these women had increased by 10times [13]. A study by Abu Hamad et al. showed a significant relationship between the history of stillbirth and preterm birth [14].

The results showed that the risk of premature birth in the mothers with a history of preterm birth was higher in the case group comparing with the control group. A study in Gaza Strip showed that there was a significant relationship between the history of preterm birth and premature birth in the next pregnancy [15]. Abaraya et al. reported that women with a history of preterm birth had a higher risk of preterm birth comparing with mothers without any history of preterm birth and the difference was significant [16]. Results of other studies have shown that the history of preterm birth has a significant relationship with preterm birth [17-20].

Distribution and diversity of $\mathrm{ABO}$ blood types depends on ethnicity, race and geographical region. For instant, the most common blood type in European countries and Japan is A and in the USA is $O$ [21]. The findings showed that the participants with $A B$ blood type in the case group had the highest risk of preterm birth comparing with the other blood types. This finding is inconsistent with [21,22]. The differences in the finding might be due to sample groups, ethical differences, and demographical differences [21].

The mothers who used specific drugs due to a disease in pregnancy had a higher risk of preterm birth. Li et al. showed that the risk of preterm birth in mothers who used hormonal drugs (OR; 2.23), blood pressure drugs (OR:7.74), and other medications (OR:2.15) during pregnancy was higher than those who did not use any medicine during pregnancy. This finding is consistent with our findings [23]. A metaanalysis study showed that the risk of preterm birth in the mother who used antidepressants (OR:1.16) during pregnancy was higher than other women [24]. A study by Huang et al. showed that mothers who used antidepressant had a higher risk of preterm birth (OR:1.69) [25].

The risk of preterm birth in the mothers with a history of pregnancy diseases was higher. A metanalysis based on population in 2007 showed that the risk of preterm birth in women with inflammatory bowel disease (IBD) was 1.87times higher than healthy mothers [26]. A study in Asia reported that the risk of preterm birth in mother with IBD was higher [27]. Several studies have shown that mothers with hypertension have a higher risk of preterm birth comparing with healthy women [18, 28-33]. In addition, the risk of preterm birth in mothers with diabetes and those who did not give diabetes tests during pregnancy was higher than the mothers without diabetes [31-34]. Sibai et al. reported that the risk of preterm birth before the 35th week in women with and without diabetes was $9 \%$ and $4.5 \%$ respectively i.e. diabetes is a risk factor of preterm birth [35]. A study by Roozbeh et al showed that urinary ducts infection during pregnancy $(35.8 \%)$ and PROM (30.3\%) were among the effective risk factors in preterm birth [36]. The results showed that there was a significant relationship between mother's disease (e.g. diabetes, hypertension, UTI, PID, and nutritional anemia) and preterm birth [15, 37]. Other studies have 
shown that the side-effects and diseases like eclampsia and placental abruption are among the risk factors of preterm birth $[38,39]$. In general, premature birth is related to the side-effects of pregnancy such as placental bleeding, higher blood pressure in pregnant women, and preeclampsia as these factor limit intrauterus development [40]. In addition, the side-effects of pregnancy hypertension may damage placental veins and stimulate oxytocin receptors, which leads to preterm delivery. Other disease like urinary ducts infections weaken amniotic membrane around the embryo and this leads to PROM and preterm birth [41]. Because these associations were inconclusive, we did not consider these factors in our study. Due to the above mentioned limitations, further studies are required for causality between risk factors and preterm births and increase sample size.

\section{Conclusion}

Mother's blood type, history of stillbirth, pregnancy disease, history of preterm birth, and history of using medicine due to specific pregnancy disease were the risk factors of preterm birth. These factors need to be taken into account in pre-pregnancy and pregnancy health cares. Through this, the health systems can lower the rate of preterm birth and mortality in mothers and infants. Knowing that preterm birth is a multicause phenomenon, identifying the risk factors and screening the mothers with such risk factors is a way to convince mother to participate in controlling the effective variables and preparing for preterm birth.

These measures lead to a lower rate of preterm and premature birth and mothers and infants' mortality in return. In addition, the majority of the factors in preterm birth are unpredictable and unavoidable; therefore, provision of health services and facilities for emergency services to these mothers and infants is essential.

\section{Abbreviations}

BMI: Body Mass Index; SD: Standard Deviation; Cl: Confidence interval; OR: Odds ratio

\section{Declarations}

Acknowledgments This article is based on Dr. Batoul Bagheri thesis on pediatrics. The authors would like to thank all patients and their family for help us to perform this study. The authors also, thank collaboration the Clinical Research Development Center of Kowsar hospital, Sanandaj, Iran

Funding This study was funded by Vice Chancellor for Research and Technology of Kurdistan University of Medical Sciences, Sanandaj, Iran. The funding body played no role in the design of the study, collection, analysis, or interpretation of data or in writing the manuscript.

Availability of data and materials The datasets used and/or analyzed during the current study can be made available by the corresponding author on reasonable request.

Authors' contributions $\mathrm{SH}, \mathrm{GM}$ and MM conceived and designed the study. SH, GM, BB and SS analyzed and interpreted the data, and drafted the manuscript. SH, MM, GM, and BB were involved in the 
composition of the study tool, supervision of the research process and critical revision and review of the manuscript. All the authors read and approved the final manuscript.

Ethics approval and consent to participate All participants were informed about the purpose and process of the study, and written informed consent for participation in the study was obtained from the participants. The approval for this study was obtained from the Ethics Committee of Kurdistan University of Medical Science (IR.MUK.REC.1398.051).

Consent for publication Not applicable.

Competing Interests The authors have no conflicts of interest to declare.

\section{References}

1. Soltani M, Tabatabaee HR, Saeidinejat S, Eslahi M, Yaghoobi H, Mazloumi E, et al. Assessing the risk factors before pregnancy of preterm births in Iran: a population-based case-control study. BMC pregnancy and childbirth. 2019;19(1):57.

2. Cupen K, Barran A, Singh V, Dialsingh I. Risk factors associated with preterm neonatal mortality: a case study using data from Mt. Hope Women's Hospital in Trinidad and Tobago. Children. 2017;4(12):108.

3. do Carmo Leal M, Esteves-Pereira AP, Nakamura-Pereira M, Torres JA, Theme-Filha M, Domingues RMSM, et al. Prevalence and risk factors related to preterm birth in Brazil. Reproductive health. 2016;13(3):127.

4. Jaberi E, Roksana M. A study on preterm births during 2013-2015, Shiraz, Iran. Journal of Obstetrics and Gynaecology. 2018;38(1):22-6.

5. Shoja M, Shoja E, Gharaei M. Prevalence and affecting factors on preterm birth in pregnant women Referred to Bentolhoda hospital-Bojnurd. Journal of North Khorasan University of Medical Sciences. 2016;7(4):855-63.

6. Blencowe H, Cousens S, Oestergaard MZ, Chou D, Moller A-B, Narwal R, et al. National, regional, and worldwide estimates of preterm birth rates in the year 2010 with time trends since 1990 for selected countries: a systematic analysis and implications. The lancet. 2012;379(9832):2162-72.

7. Dolatian M, Mirabzadeh A, Forouzan AS, Sajjadi H, Alavimajd H, Mahmoodi Z, et al. Relationship between structural and intermediary determinants of health and preterm delivery. Journal of reproduction \& infertility. 2014;15(2):78.

8. https://www.who.int/news-room/fact-sheets/detail/preterm-birth.

9. Beck S, Wojdyla D, Say L, Betran AP, Merialdi M, Requejo JH, et al. The worldwide incidence of preterm birth: a systematic review of maternal mortality and morbidity. Bulletin of the World Health Organization. 2010;88:31-8.

10. Rao CR, de Ruiter LE, Bhat P, Kamath V, Kamath A, Bhat V. A case-control study on risk factors for preterm deliveries in a secondary care hospital, southern India. ISRN obstetrics and gynecology. 
2014;2014.

11. Goldenberg RL, Culhane JF, lams JD, Romero R. Epidemiology and causes of preterm birth. The lancet. 2008;371(9606):75-84.

12. Ahumada-Barrios ME, Alvarado GF. Risk Factors for premature birth in a hospital. Revista latinoamericana de enfermagem. 2016;24.

13. Malacova E, Regan A, Nassar N, Raynes-Greenow C, Leonard H, Srinivasjois R, et al. Risk of stillbirth, preterm delivery, and fetal growth restriction following exposure in a previous birth: systematic review and meta-analysis. BJOG: An International Journal of Obstetrics \& Gynaecology. 2018;125(2):18392.

14. Abu Hamad K, Abed Y, Abu Hamad B. Risk factors associated with preterm birth in the Gaza Strip: hospital-based case-control study. 2007.

15. Al-Joborae SFF, Alwan FW. Sociodemographic and medical factors of preterm delivery according to the clinical subtypes of prematurity. Medical Journal of Babylon. 2018;15(4):341-8.

16. Abaraya M, Seid SS, Ibro SA. Determinants of preterm birth at Jimma University Medical Center, southwest Ethiopia. Pediatric health, medicine and therapeutics. 2018;9:101.

17. Ip M, Peyman E, Lohsoonthorn V, Williams MA. A case-control study of preterm delivery risk factors according to clinical subtypes and severity. Journal of Obstetrics and Gynaecology Research. 2010;36(1):34-44.

18. Alijahan R, Hazrati S, Mirzarahimi M, Pourfarzi F, Ahmadi Hadi P. Prevalence and risk factors associated with preterm birth in Ardabil, Iran. Iranian journal of reproductive medicine. 2014;12(1):4756.

19. Farrant BM, White SW, Shepherd CC. Trends and predictors of extreme preterm birth: Western Australian population-based cohort study. PloS one. 2019;14(3):e0214445.

20. Dekker GA, Lee SY, North RA, McCowan LM, Simpson NA, Roberts CT. Risk factors for preterm birth in an international prospective cohort of nulliparous women. PloS one. 2012;7(7):e39154.

21. Phaloprakarn C, Tangjitgamol S. Maternal ABO blood group and adverse pregnancy outcomes. Journal of Perinatology. 2013;33(2):107.

22. Pereira N, Patel HH, Stone LD, Christos PJ, Elias RT, Spandorfer SD, et al. Association between ABO blood type and live-birth outcomes in single-embryo transfer cycles. Fertility and sterility. 2017;108(5):791-7.

23. Li MM, Li C, Zhang BY, Wu WT, Gao XY, Wu CL, et al. [Relationship between preterm birth of infant and medication during pregnancy in women of childbearing age in Shaanxi]. Zhonghua liu xing bing xue za zhi = Zhonghua liuxingbingxue zazhi. 2019;40(5):554-8.

24. Huybrechts KF, Sanghani RS, Avorn J, Urato AC. Preterm birth and antidepressant medication use during pregnancy: a systematic review and meta-analysis. PLoS One. 2014;9(3):e92778.

25. Huang H, Coleman S, Bridge JA, Yonkers K, Katon W. A meta-analysis of the relationship between antidepressant use in pregnancy and the risk of preterm birth and low birth weight. General hospital 
psychiatry. 2014;36(1):13-8.

26. Cornish J, Tan E, Teare J, Teoh TG, Rai R, Clark SK, et al. A meta-analysis on the influence of inflammatory bowel disease on pregnancy. Gut. 2007;56(6):830-7.

27. Lin HC, Chiu CC, Chen SF, Lou HY, Chiu WT, Chen YH. Ulcerative colitis and pregnancy outcomes in an Asian population. The American journal of gastroenterology. 2010;105(2):387-94.

28. Madan J, Chen M, Goodman E, Davis J, Allan W, Dammann O. Maternal obesity, gestational hypertension, and preterm delivery. The journal of maternal-fetal \& neonatal medicine : the official journal of the European Association of Perinatal Medicine, the Federation of Asia and Oceania Perinatal Societies, the International Society of Perinatal Obstet. 2010;23(1):82-8.

29. Ye RW, Li HT, Ma R, Ren AG, Liu JM. [Prospective cohort study of pregnancy-induced hypertension and risk of preterm delivery and low birth weight]. Zhonghua yu fang yi xue za zhi. Chinese journal of preventive medicine. 2010;44(1):70-4.

30. Manuck TA, Esplin MS, Biggio J, Bukowski R, Parry S, Zhang H, et al. The phenotype of spontaneous preterm birth: application of a clinical phenotyping tool. American journal of obstetrics and gynecology. 2015;212(4):487.e1-.e11.

31. Yanit KE, Snowden JM, Cheng YW, Caughey AB. The impact of chronic hypertension and pregestational diabetes on pregnancy outcomes. American journal of obstetrics and gynecology. 2012;207(4):333.e1-6.

32. Bramham K, Parnell B, Nelson-Piercy C, Seed PT, Poston L, Chappell LC. Chronic hypertension and pregnancy outcomes: systematic review and meta-analysis. BMJ (Clinical research ed). 2014;348:g2301.

33. Premkumar A, Henry DE, Moghadassi M, Nakagawa S, Norton ME. The interaction between maternal race/ethnicity and chronic hypertension on preterm birth. American journal of obstetrics and gynecology. 2016;215(6):787.e1-.e8.

34. Khalajinia Z, Gholamreza J. Maternal risk factors associated with preterm delivery in Qom province of Iran in 2008. Scientific Research and Essays. 2012;7(1):51-4.

35. Sibai BM, Caritis S, Hauth J, Lindheimer M, VanDorsten JP, MacPherson C, et al. Risks of preeclampsia and adverse neonatal outcomes among women with pregestational diabetes mellitus. National Institute of Child Health and Human Development Network of Maternal-Fetal Medicine Units. American journal of obstetrics and gynecology. 2000;182(2):364-9.

36. Roozbeh N, Moradi S, Soltani S, Zolfizadeh F, Hasani MT, Yabandeh AP. Factors associated with preterm labor in Hormozgan province in 2013. Electronic physician. 2016;8(9):2918-23.

37. Abdelhady AS, Abdelhady A. Rate and risk factors of preterm births in a secondary health care facility in Cairo. World Journal of Medical Sciences. 2015;12(1):9-16.

38. El Mhamdi S, El Ghardallou M, Salah AB, Bouanene I, Sriha A, Salem KB, et al. Epidemiological and chronological profile of preterm birth in the region of Monastir (Tunisia) between 1994 and 2012. Eastern Mediterranean Health Journal. 2015;21(1). 
39. Boivin A, Luo Z-C, Audibert F, Mâsse B, Lefebvre F, Tessier R, et al. Pregnancy complications among women born preterm. Cmaj. 2012;184(16):1777-84.

40. Bertagnolli M, Luu TM, Lewandowski AJ, Leeson P, Nuyt AM. Preterm Birth and Hypertension: Is There a Link? Current hypertension reports. 2016;18(4):28.

41. Devlieger R, Millar LK, Bryant-Greenwood G, Lewi L, Deprest J. Fetal membrane healing after spontaneous and iatrogenic membrane rupture: a review of current evidence. American journal of obstetrics and gynecology. 2006;195(6):1512-20.

\section{Supplementary Files}

This is a list of supplementary files associated with this preprint. Click to download.

- STROBEchecklistcasecontrol.pdf 